\title{
Preliminary evidence that overexpression of nuclear fac- tor for IL6 expression (NF-IL6) in NIH3T3 cells may be related to malignant transformation
}

\author{
ZHU Minsheng*, Dinggan LIU*1, Shizuo Akira**, \\ Z IPING LI*. \\ *Shanghai Institute of Biochemistry, Academic Sinica, \\ Shanghai 200031, China \\ **Institute of Molecular and Cellular Biology, Osaka Uni- \\ versity, Japan.
}

\begin{abstract}
NF-IL6 is a member of c/EBP family and has multiple functions in regulation of cellular gene expression. We have constructed NF-IL6 expression plasmids and trans. fected the NIH3T3 cells with them. The sense NF-IL6 transfectants showed significantly increased tumorigenicity, and the stable integration of NF-IL6 cDNA into cellular DNA and its expression were demonstrated. Our results suggest that NF-IL6 may be related to tumorigenesis.
\end{abstract}

Key words: NF-IL6, NIH3T3, tumorigenicity

\section{INTRODUCTION}

NF-IL6, a member of c/ $\operatorname{EBP} \beta[1]$, is a transcription factor for IL- 6 expression. It is characterized as a nuclear factor binding to a $14 \mathrm{bp}$ palindrimic sequence (AGATTGCACAATCT) within an IL-1 responsive element in the human IL-6 gene[2,3]. The cloned NF-IL6[1,3-7] contains a region highly homologous to the C-terminal portion of $\mathrm{c} / \mathrm{EBP}$, and it is being considered as a member of $\mathrm{c} / \mathrm{EBP}$ family. It is shown that NF- IL6 binds to the transcriptional regulatory region found in several acute- phase genes and other cytokine genes, including TNF, IL-8 and G-CSF etc., implying that NF-IL6 may be involved in the regulation of acutephase reaction, inflammation and hemopoiesis[8]. NF- IL6 expression is increased during tissue inflammation or neoplastic transformation, e.g. NF-IL6 is expressed

1. Corresponding author 
NF-IL6 and malignant transformation of NIH3T3 cells

constitutively in human hepatoma HepG2, HepG3B and ovary cancer CHU2 cells[3]. However, the relationship of NF- IL6 to tumorigenesis has been largely unknown.

In our previous work, we identified a cDNA clone with antioncogene activity $[9,10]$ and it was shown to be the 3-untranslated region of NF- IL6 cDNA[11] (Liu, DG, personal communication to Helen M. Blau, 1992). Therefore, we are intersted in the possible role of NF- IL6 in tumorigenesis. In this report, we have found that stable overexpression of NF-IL6 in NIH3T3 cells may be, in some way, related to their malignant transformation.

\section{MATERIALS AND METHODS}

\section{Cells, plasmids, enzymes and chemicals}

The NIH3T3 cells were obtained from Prof. Yuan Wang and cultured in our laboratory. The pBlue610, a clone of the NF-IL6 cDNA, was constructed by Akira S.[3]. Plasmid pSVL was purchased from Pharmacia. Plasmid pSV2-neo was a gift of Dr. Makoto NODA. Plasmids pSP64 and pSP65 were gifts of Prof. Yong-lian ZHANG. Restriction endonucleases were from BoehringerMannheim Sigma and Sino-American Biotechnology Co.\# Hybridization membranes were from BioRad and Amersham. Cell culture media and sera were from Sigma and Gibco/BRL. The other reagents were of reagent grade or analytical grade, or of higher purity.

\section{Recombinant DNA technology}

Recombinant DNA work was done according to standard methods[12].

\section{Cell culture and DNA transfection}

NIH3T3 cells were cultured in Dulbecco's modified Eagle medium(DMEM) supplemented with $5 \%$ fetal bovine serum and antibotics. The NIH3T3 cells at $24 \mathrm{~h}$ after plating $\left(2 \times 10^{5}\right.$ cells per $50 \mathrm{ml}$ flask) were co-transfected with $20 \mu \mathrm{g}$ per flask of recombinant pSVL and $4 \mu \mathrm{g}$ of a control plasmid containing neo gene by calcium phosphate method[12]. Stable transfectants were obtained by selection with $1 \mathrm{mg} / \mathrm{ml}$ of G418. The G418 concentration was lowered to $0.75-0.5 \mathrm{mg} / \mathrm{ml}$ when the G418 resistant cells appeared.

\section{Tumorigenicity assay in nude mice}

Cells in late log phase were harvested with trypsinization, washed once with Hanks solution and resuspended in DMEM. $0.2 \mathrm{ml}$ of cell suspensions were injected subcutaneously into the back and both sides of abdomen of 4 to 5 week-old Balb/c nu/nu nude mice, with 4-6 $610^{5}$ cells for each injection site. Animals were regularly examined for tumor growth. At the 14th day postinjection, the mice were sacrificed, tumors were dissected and their wet weights were determined.

\section{RNA extraction}

One-step method described by Chomczynski[13] was used. Briefly, nude mice tumors were pulverized under liquid nitrogen in a porcelain mortar and then dissolved in one volume of GIT solution (4.0 M guanidinium thiocyanate, $0.1 \mathrm{M}$ Tris.Cl pH 7.4, $1 \%$ 2-mercaptoethanol), then $0.1 \mathrm{~V}$ of $2 \mathrm{M}$ $\mathrm{NaAc}, \mathrm{pH} 4$ and $1 \mathrm{~V}$ of water- saturated phenol were added sequentially, with thorough gentle mixing after each adding. Finally, $0.2 \mathrm{~V}$ of chloroform were added, voltex-mixed. After standing on ice for $15 \mathrm{~min}$, the mixture was centrifuged at 12,000 rpm. The RNA in aqueous phase was precipitated with equal volume of isopropanol and the pellet was dissolved in 0.3 volume of GIT and then precipitated once again. The final RNA pellet was dissolved in $0.5 \%$ SDS, stored at -70 ${ }^{\circ} \mathrm{C}$, and ethanol precipitated once again prior to use. 


\section{RNase protection assay and Southern hybridization}

RNase protection was performed according to literature[12] , using Promega Riboprobe II core system and $\left[\alpha_{-}{ }^{32} \mathrm{P}\right]$-UTP to synthesize radiolabeled RNA probe.Southern hybridization was performed according to literature[12], using BioRad's Zeta-probe and Amersham's nylon membranes.

\section{RESULTS}

\section{Construction of recombinant plasmids containing NF-IL6 cDNA insert}

The sense and antisense NF-IL6 expression plasmids were constructed by subcloning the SalI-SalI fragment of the plasmid pBlue610, harboring NF-IL6 coding region, into XhoI site of tke eukaryotic expression vector pSVL. The orientations of the NF-IL6 insert was confirmed by using SacI digestion and agarose electrophoresis. The sense- oriented recombinant plasmid, pSVL/NF-S, yielded 3 fragments, 5.5, 0.39 and $0.15 \mathrm{~kb}$ in length respectively, while antisense one, pSVL/NF-AS, gave 5.0, 0.5 and $0.39 \mathrm{~kb}$ fragments respectively (Fig 1 ).

For RNase protection assay, we also constructed recombinant pSP64 and pSP65 plasmids, containing the $150 \mathrm{bp}$ PstI-SalI fragment near the 3 '-terminus of the NFIL6 cDNA coding region, which was thought to be optimal for probing the NFIL6 gene. pSP64/NF- 100 contains this fragment in the sense orientation, and pSP65/NF100 contains it in the antisense orientation.

\section{NF-IL6 gave rise to tumorigenicity of NIH $3 T 3$ cells}

In order to evaluate the consequences of increased or decreased expression of NF-IL6 in tumor formation, we transfected NIH3T3 cells with pSV2-neo and various NF-IL6 constructs (pSVL/NF-S, pSVL/NF-AS and pSVL as described above). Cells transfected with the construct of NF -IL6 in sense orientation were called sense line, and so on. All the G418 resistant transfectant lines showed transformed morphology (data not shown). Initially, we were not sure if these cells would display tumorigenicity, so all the clones from each transfection were taken together, without clone selection, for the tumorigenicity experiments. When Balb/c nu/nu nude mice were inoculated with each of the transformed cell lines at doses of $4 \times 10^{5}$ and $6 \times$ $10^{5}$ cells per point of injection,every line gave rise to tumors. There were variations in the sizes of tumors formed from injected cells, as shown in Tab 1 and Fig 3. We think this discrepancy may be due to error of injection, as well as to the individual variation of animals. The tumor-forming rate of sense line is higher than that of pSVL or antisense line, but no statistical significance was observed. However, the tumors formed by antisense and pSVL control lines showed slower growth rate and smaller sizes, and no significance was observed between these two control groups $(\mathrm{P}>0.05)$. In contrast, the tumors formed by the sense line showed higher growth rate and larger sizes. An obviously significant difference in tumor size $(\mathrm{P}<0.05)$ compared with the tumors formed from antisense and control lines was observed, as 
NF-IL6 and malignant transformation of NIH3T3 cells

shown in Fig 2. Similar result was obtained by comparing tumor weight as shown in Tab 1.

Tab 1. Tumor-forming properties of NIH3T3 cells transfected with NF-IL6 recombinants

\begin{tabular}{|c|c|c|c|c|}
\hline \multirow{3}{*}{$\begin{array}{l}\text { Transfectant } \\
\text { line }\end{array}$} & \multicolumn{2}{|c|}{$\begin{array}{l}\text { Wet weights of formed tumors* } \\
\qquad(\mathrm{X} \pm \mathrm{SD}) \mathrm{g}\end{array}$} & \multicolumn{2}{|c|}{ Tumors/total injedcion points } \\
\hline & \multicolumn{2}{|c|}{$\begin{array}{l}\text { Cells in a single injection } \\
(0.2 \mathrm{ml} \text { per point })\end{array}$} & \multicolumn{2}{|c|}{$\begin{array}{c}\text { Cells in a single injection } \\
(0.2 \mathrm{ml} \text { per point })\end{array}$} \\
\hline & $4 \times 10^{5}$ & $6 \times 10^{5}$ & $4 \times 10^{5}$ & $6 \times 10^{5}$ \\
\hline pSVL line & $0.39 \pm 0.29$ & $0.46 \pm 0.47$ & $4 / 6$ & $5 / 7$ \\
\hline NF-AS line & $0.53 \pm 0.39$ & $0.60 \pm 0.19$ & $5 / 6$ & $6 / 7$ \\
\hline NF-S line & $0.74 \pm 0.75$ & $1.96 \pm 0.87$ & $7 / 7$ & $7 / 7$ \\
\hline
\end{tabular}

* Tumor-bearing mice were sacrificed at the 14 th day.

\section{Stable integration and expressionof NF-IL6 gene in transfectants}

Then we investigated if the cells that formed tumors when injected into nudemice really contained the NF-IL6 recombinants used in transfection. Based on the structure of the recombinant plasmids, we have assumed that, when the cellular DNA integrated with pSVL/NF-S was digested with SacI and KpnI, a 150bp NF-IL6 cDNA fragment should be cut off; while when the cellular DNA with pSVL/NF-AS was digested with the same enzymes, a fragment of $1.3 \mathrm{~kb}$ in length should appear. Both fragments should be detected by hybridization respectively. No specific hybridization band should be found in the control pSVL-integrated cellular DNA (refer in Fig 1A). With these assumptions in mind, we checked the status of integrated NF-IL6 in various cell lines. Southern blots showed that both sense or antisense NF-IL6 were inserted into cellular genomic DNA as anticipated. As shown in Fig 3, there was a hybridization band, about 5 copies per cell, as estimated from control hybridizations with calculated amounts of the probe, at $150 \mathrm{bp}$ position in lane pSVL /NF-S; and a hybridization band, about 5 copies per cell, at $1.3 \mathrm{~kb}$ position was observed in lane pSVL /NF-AS; and no specific hybridization band was found for control genomic DNA, lane pSVL.

Fig 1. $\triangleright$ Construction of NF-IL6 expression plasmids. Fragments digested from pBlue610 with SalI was inserted into pSVL expression plasmid digested with XhoI. SacI digestion of recombinant plasmid with the fragment inserted in sense orientation (A:pSVL/NF-S and B: lane S) revealed three bands of $0.15,0.39$ and $5.5 \mathrm{~kb}$, while in antisense orientation (A: pSVL/ NF-AS snd B: lane AS), it revealed three bands of $0.39,0.5$ and $5.0 \mathrm{~kb}$. SacI digestion of pSVL plasmid (pSVL) showed no extra band apart from a single band of the vector. 
Zhu MS et al.

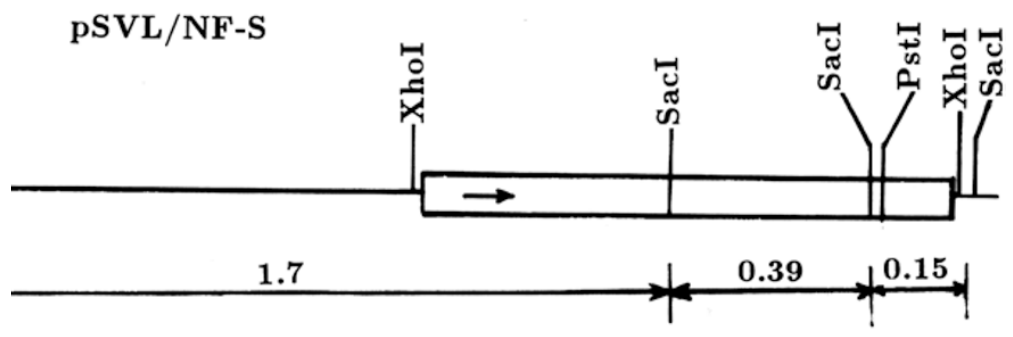

pSVL/NF- AS
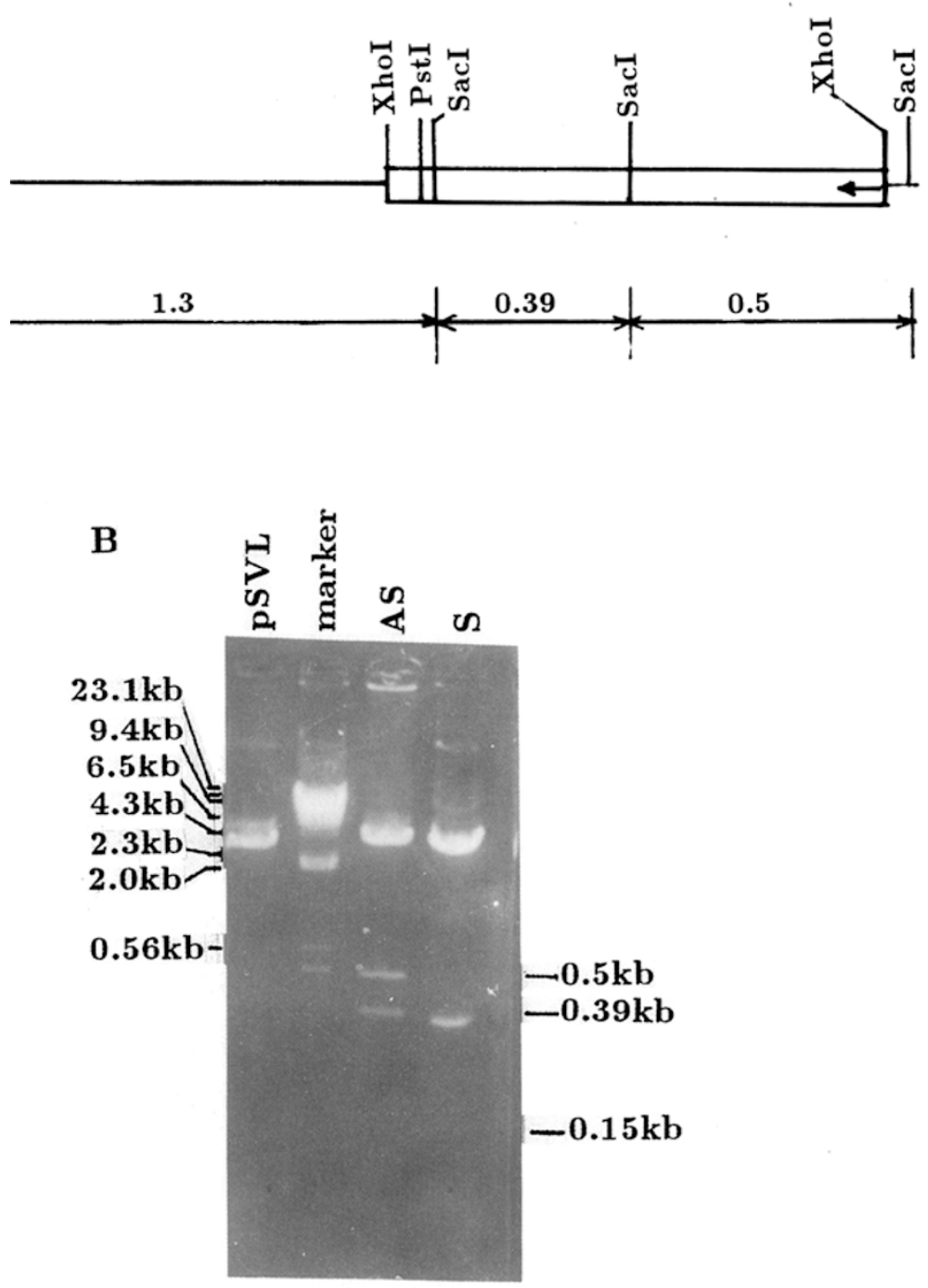
NF-IL6 and malignant transformation of NIH3T3 cells

Fig 2. Growth characteristics of the tumors formed by NF- IL6 transfectants of NIH3T3 cells. Balb/c nu/nu mice (4 to 5 weeks old) were injected with $6 \times 10^{5}$ transfectant cells per injection point and the tumor diameters were measured at different time. Tumors of pSVL/NF- AS ( $\boldsymbol{\Delta})$ and pSVL $(-)$ groups grew slowly and attained to a smaller size at the end of observation period on the 14th day. Tumors of pSVL / NF-S (ם) group became visible about 2 to 3 days earlier than those of other groups, and the tumor size reached to 3-fold over those of pSVL and pSVL/ NF-AS tumors. Arrows indicate the day of first appearance of tumor.

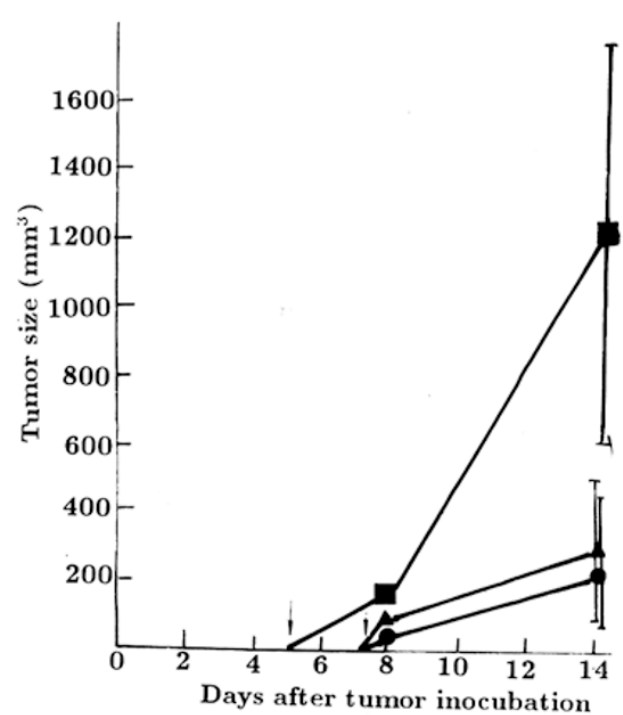

The results of RNase protection assay showed that NF-IL6 mRNA was highly expressed in mice tumors formed by the sense line, while its expression was not detected in the tumors from antisense and control transfectants (Fig 4). We have been unable as yet to demonstrate the presence of antisense transcripts in the antisense transfectants. Similar difficulties in demonstrating the presence of antisense transcripts in eukaryotic systems have been noted by other investigators[14, 15]. A possible mechanism was involved the dsRNA unwinding modifying activity[16].

In conclusion,we have found that transfection of sense,expressible NF-IL6 coding region into NIH3T3 cells may result in their malignant transformation.

\section{DISCUSSION}

NIH3T3, a mouse fibroblast cell line, has long been used as a sensitive detector of transforming genes. In this work, we used various NF-IL6 constructs to transfect this cell line, in order to elucidate if NF-IL6 could exert any transforming gene-like effect. We really found that sense NF-IL6 markedly increased tumor growth rate of its transfectant, comparing with other control transfectants. At the same time, the NF-IL6 was found to be stably integrated into transfectants and expressed. Therefore, in our experiments, the NF-IL6 significantly promoted growth of tumors formed by sense line. In this respect it mimics characteristics of a transforming gene in behavior.

It is already noted by other authors[3] that NF-IL6 is differentially expressed in normal tissue and in tumors. In normal liver, NF-IL6 is underexpressed, but in hepatoma the expression of NF-IL6 is significantly increased. However, a more or 
less similar phenomenon of ras gene was also reported[17]. In a pheochromocytoma cell line, PC12, transfection of active ras gene led this line to acquire normal neuronlike morphology and cease to proliferate. This might indicate that some oncogenic proteins involved in signal transduction have dual functions. This is understandable when one imagines that tumor cells can share the same normal signal transduction pathway. Our experiments, however, are the direct demonstration of tumorigenic property of the NF-IL6, at least in vitro.

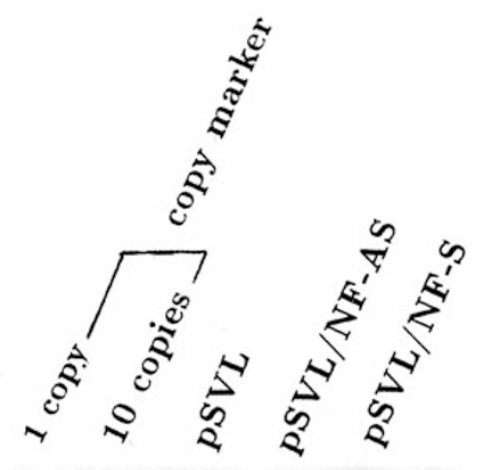

$-1.3 \mathrm{~kb}$

$-150 \mathrm{~kb}$

Fig 3. Integration of recombinant plasmid into NIH3T3 cellular DNA. Twenty micrograms of DNA from pSVL (lane pSVL), pSVL/NF-AS (lanepSVL / NF -AS ) and pSVL / NF-S (lane pSVL/NF-S) tumors were digested with KpnI/SacI and subjected to hybridization using a 150bp of pBlue610 PstI/SacI fragment labeled with $5\left[\alpha-{ }^{32} \mathrm{P}\right] \mathrm{dATP}$ by random primer synthesis. Arrows indicate the expected hybridization fragments of $1.3 \mathrm{~kb}$ or $0.15 \mathrm{~kb}$, as shown in Fig 1 . Lambda/HindIII fragments were used as molecular weight marker. DNA copy markers were prepared according to the formula: probe DNA weight $(\mu \mathrm{g})$ for 1 copy $=\left(150 \mathrm{bp} / 3 \times 10^{9} \mathrm{bp}\right) \times$ weight of total cellular DNA $(\mu \mathrm{g})$. 
NF-IL6 and malignant transformation of NIH3T3 cells

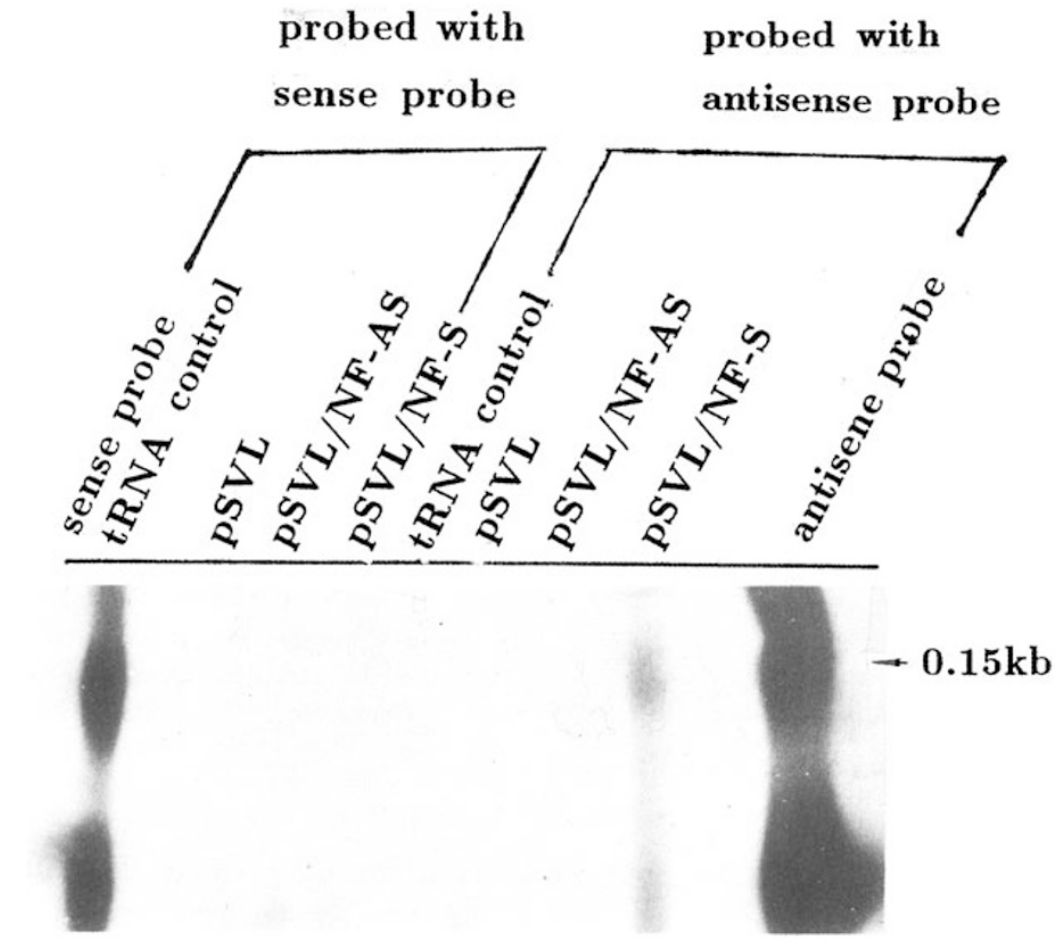

Fig 4. RNase protection assay for different NF- IL6 transfectants. Total RNA $(20 \mu \mathrm{g})$ was hybridized with $5,\left[\alpha-{ }^{32} \mathrm{P}\right]$ UTP labeled antisense probe transcripts from pSP65/NF- 100 linear plasmid. The antisense probe (right part of the photo) was protected by sense NF- IL6 mRNA (the band showed in lane pSVL/NF-S of right part of photo) and no protection signals were found in lane of pSVL, pSVL /NF- AS and tRNA control; The labeled sense probe ( left part of photo) prepared from pSP64/NF-100 failed to be protected by RNA of pSVL tumor, sense NF-IL6 tumor, tRNA control and even by RNA of antisense NF-IL6 tumor. Arrow indicates the size of probe.

It is well known that NF-IL6 is involved in the signal transduction pathway from cellular surface receptor to target genes. This pathway includes many protein kinases[8]; and it is found that the Ras protein is also involved in this pathway[18]. If it is true, the NF-IL6 might possibly share part of the pathway with Ras protein, and have some transforming potential as Ras protein does.

According to our results in this report, NF-IL6 is undetectable in NIH3T3 cells and when NF-IL6 expression level was lowered further by introducing its antisense cDNA, no difference in tumorigenicity was observed.It is not difficult to understand it when we realize that NF-IL6 was rarely expressed or expressed in very low level under normal condition.

In our experiments, control cell line containing pSVL and pSV2-neo only also 
showed transformed phenotype and gave rise to tumorigenicity of NIH3T3 cells. This phenomenon may be related to the cellular inherent unstability, especially under abnormal environmental situations, including the conditions associated with DNA transfection and, even the type and concentration of bovine serum used in medium and the passage history of cells[19] etc.. Additionally, it has been reported that transfection with pSV2-neo control plasmid may result in spontaneous conversion of metastatic phenotype in embryonic fibroblast cells[20, 21]. Therefore, the occurrence of the transformation phenotype and tumorigenicity of NIH3T3 cells after transfection with plasmid DNAs is under- standable. As for occurrence of tumorigenicity of antisense NF-IL6 transfectant, it may be explained as that introducing antisense NF-IL6 made no difference in NF-IL6 expression level and, then , in transformation behavior compared with control transfectant.

Since NF-IL6 gene we used was cloned from cDNA libary of human glioblastoma cell lines, it would be interesting to know if NIH3T3 cells will be transformed after transfection of mouse homolog of NF-IL6, or cultured human cells transfected with human homolog of NF-IL6. All these need further studies.

\section{ACKNOWLEDGMENTS}

We would like to thank Mr. Fong LIU and Zhao-Hui LI for assistance in tumorigenicity experiments. We would also like to thank professor Tadamitsu KISHIMOTO for help. This work is supported by a grant from the 863 program, National Science and Technology Commission, China.

\section{REFERENCES}

[1] Cao Z, Umek RM, McKnight SL. Regulated expression of three c/EBP isoforms during adipose coversion of 3T3-L1 cells. Gene \& Dev 1991; 5:1538.

[2] Isshiki H, Akira S, Tanabe o, Nakajima Y, Shimamoto T. Hirano T, Kishimoto T. Constitutive and interleukin-1 (IL- 1) -responsive element in the interleukin-6 gene. Mol Cell Biol 1990; 10:2757.

[3] Akira S, Isshiki H, Sugita T, Tanabe O, et al. A nuclear factor for IL-6 expression (NF-IL6) is a member of a c /EBP family. EMBO J 1990; 9:1897.

[4] Chang CJ, Chen TT, Lei HY, Chen DS, Lei SC. Molecular cloning of a transcription factor AGP/EBP, that belong to members of the c/EBP family. Mol Cell Biol 1990; 10:6642.

[5] Williams SC, Cantwell CA, Johnson PF. A family of c /EBP- related proteins capable of forming covalently linked leucine zipper dimers in vitro. Gen \& Dev 1991; 5:1553.

[6] Descombes P, Chojkier M, Lichtsteiner S, Falvey E, Schibler V. LAP, a novel member of the c/EBP gene family, encodes a liver- enriched transcriptional activator protein. Gen \& Dev 1990; 4:1541.

[7] Poli v, Mancini FP, Cortese R. IL-6DBP, a nuclear protein involved in interleukin-6 signal transduction, defines a new family of leucine zipper proteins related to c/EBP. Cell 1990; 63:643.

[8] Kishimoto T, Akira S, Taga T. Interleukin 6 and its receptor: A paradigm for cytokines. Science 1992; 258:593.

[9] Liu DG, Wang D, Chen ZZ, Li ZP. A cDNA with antioncogene activity. SCI China (series B) (in Chinese) 1991; 7:730. 


\section{NF-IL6 and malignant transformation of NIH3T3 cells}

[10] Liu DG, Zhu LH, Chen ZZ, Noda M, Guo LH, Li ZP. Nucleotide sequence of cDNA clone with antioncogene activity. Chinese J Biochem Biophy 1991; 24:261

[11] Liu DG, Li ZP, Akira S, Kishimoto T. Overexpression of a reversion -related protein in revertant cell line RR. Sci China (series B). 1994; to be published.

[12] Sambrook J, Fritsch EF, Maniatis T. Molecular cloning:A laboratory manual. 2nd edition. CSH press. 1989.

[13] Chomczynski P, Sacchi N. Single-step method of RNA isolation by acid guanidinium thiocyanatephenol-chloroform extraction. Anal Biochem. 1987; 162:156.

[14] Kasid U, Pfeifer A, Brennan T, et al. Effect of antisense c- raf- 1 on tumorigenicity and radiation sensitivity of human squamous carcinoma. Science 1989; 243:1354.

[15] Contente S, Kenyon K, Rimoldi D, Friedman RM. Expression of gene rrg is associated with reversion of NIH3T3 transformed by LTR-c-H-ras. Science 1990; 249:796.

[16] Nishikura K. Gene regulation: Biology of antisense RNA and DNA. Erickson RP, Izant JG.(eds). Raven Press, Ltd.., New York 1992:21.

[17] Noda M, Ko M, Oura A, et al. Sarcoma virus carrying ras oncogenes induce differentiation associated properties in a neuronal cell line. Nature 1985; 318:73.

[18] Nakajima T, Kinoshita S, Sasagawa T, et al. Phosphorylation at threonine-235 by a rasdependent mitogen- activated protein kinase cascade is essential for transcription factor NF-IL6. PNAS USA 1993; 90:2207.

[19] Nicolson GL, Gallick GE, Spohn WH, Lembo TM, Tainsky, MA. Transfection of activated c-H-ras EJ/pSV2-neo or pSV2-neo genes into rat mammary cells:rapid stimulation of clonal diversification of spontaneous metastatic and cell-surface properties. Oncogene 1992; 7:1127.

[20] Kerbel RS, Waghorne C, Man MS,Elliot B, Breitman ML. Alteration of the tumorigenic metastatic properties of neoplastic cells is associated the process of calcium phosphate-mediated DNA transfection .PNAS USA 1987; 84:1263.

[21] Rubin $\mathrm{H}$ and $\mathrm{Xu} \mathrm{K}$. Evidence for the progressive and adoptive nature of spontaneous transformation in the NIH3T3 cells. PNAS USA 1989; 86:1860.

Received 20-10-1994. Revised 14-12-1994. Accepted 14-12-1994. 